The University of Maine

\title{
DigitalCommons@UMaine
}

Psychology Faculty Scholarship

Psychology

Summer 1997

\section{Preventive Intervention as Means of Clarifying Direction of Effects in Socialization: Anxious- Withdrawn Preschoolers Case}

Peter J. LaFreniere

University of Maine - Main, peter_lafreniere@umit.maine.edu

France Capuano

University of Sherbrooke

Follow this and additional works at: https://digitalcommons.library.umaine.edu/psy_facpub

Part of the Psychology Commons

\section{Repository Citation}

LaFreniere, Peter J. and Capuano, France, "Preventive Intervention as Means of Clarifying Direction of Effects in Socialization: Anxious-Withdrawn Preschoolers Case" (1997). Psychology Faculty Scholarship. 1.

https://digitalcommons.library.umaine.edu/psy_facpub/1 


\title{
Preventive intervention as means of clarifying direction of effects in socialization: Anxious-withdrawn preschoolers case
}

\author{
PETER J. LAFRENIERE ${ }^{a}$ AND FRANCE CAPUANO ${ }^{b}$ \\ ${ }^{a}$ University of Maine; and ${ }^{b}$ University of Sherbrooke
}

\begin{abstract}
An indicated preventive intervention research program integrating attachment, attributional, and behaviorist perspectives was conducted to test the hypothesis that parent-child relationship disturbances directly effect the child's adjustment to the preschool. Anxious-withdrawn preschool children and their mothers were divided equally into treatment and control groups, and assessed on maternal self-report of parenting stress, behavioral ratings of mother-child interaction, and teacher ratings of the children in the preschool classroom. Results showed significant changes in the treatment group: mothers in the treatment group moderated their level of control to a more appropriate, less intrusive level, while children in the treatment group showed an increase in cooperation and enthusiasm during a problem solving task with mother. Teacher-rated social competence and anxious-withdrawn behavior indicated improvement, although only the former was significant. The demonstration of effects of this home intervention for the mother on the child's behavior in the preschool confirm the transactional model underlying this study and demonstrate the utility of a parent-child interaction training component for the prevention of behavioral-emotional problems in young children.
\end{abstract}

While the study reported herein may be viewed as an applied study in preventive intervention research (Greenberg, Kusche, Cook, \& Quamma, 1995; Muehrer \& Koretz, 1992; Strayhorn \& Weidman, 1991), it was designed as basic research to clarify direction of effects within a transactional model of the development of anxious-withdrawn behavior in early childhood. From this latter perspective, we seek to test the general hypothesis that many emotional problems of young children are best conceptualized as relationship disturbances (Emde, 1989; Sroufe, 1989;

This research was supported by grants from the Social Sciences and Research Council of Canada and the Fonds pour la Formation de Chercheurs et l'Aide a la Recherche to the first author. A preliminary version of this article was presented at the biennial meeting of the Society for Research in Child Development, Indianapolis, March 1995.

Address correspondence and reprint requests to: Peter LaFreniere, Department of Psychology, 362 Little Hall, University of Maine, Orono, ME 00469. E-mail: Peterlaf @Maine.Maine.Edu.
Sroufe \& Fleeson, 1986). In this view, affective and behavioral symptoms of the child may be strongly influenced by ongoing difficulties of the caregiver that alter the quality of the parent-child relationship. If this is true, it follows that effectively addressing those difficulties may alleviate the symptoms expressed by the child.

In addition to this research objective, this study provides an opportunity to help bridge the gap between professionals who provide psychotherapeutic interventions to children and the developmental research community. The historic divide between these two realms is being gradually reduced through meaningful dialogue, partly as a result of the emergence of developmental psychopathology as a hybrid discipline (Cicchetti \& Toth, 1992), but also partly as a result of the increasing societal needs of families and children and a growing recognition among developmental researchers of the urgency of meeting those needs. In an influential statement of the goals 
and objectives of developmental psychopathology, Sroufe and Rutter (1984) outlined an approach that involves a reciprocal interplay between basic research on normative development and research on high risk or pathological populations arguing that such an approach not only deepens one's understanding of development, but that one also gains valuable information for primary prevention. In this paper we shall argue for another aspect of this reciprocal interplay: that as one deepens one's understanding of the processes of primary prevention, one also gains valuable information for developmental theory. While the logic underlying such an approach has been articulated previously (Cicchetti, 1993; Kellam, 1990; Koretz, 1991), we do not yet have an extensive data base from which to draw firm conclusions, particularly during the preschool period. It is our intent to add empirical findings to this data base by incorporating a transactional model in the identification and treatment of the anxious-withdrawn preschool child, rather than treatment of the discrete child-specific symptoms in the setting in which they are displayed.

While not yet common, the idea of conducting developmentally based preventive interventions as a means of testing developmental theory is not without precedent. For example, attachment researchers have recently introduced experimental designs involving therapeutic interventions as a means of confirming transactional models as well as evaluating therapeutic approaches (Cicchetti, Toth, \& Lynch, 1995; Erickson, Korfmacher, \& Egelund, 1992; Jacobson \& Frye, 1991; Lieberman, Weston, \& Pawl, 1991). These studies provide experimental evidence in support of distal factors influencing quality of attachment consistent with earlier nonexperimental designs. Based on Crockenberg's (1991) correlational study linking maternal social support to quality of attachment, Jacobson and Frye (1991) report experimental evidence regarding the impact of increased social support during the first postpartum year on QSort measures of attachment at 14 months. Lieberman et al. (1991), using a similar design, provide evidence that a 1-year-long program involving infant-parent therapy based on attachment theory can enhance maternal empathy and sensitivity to the child's developmental needs and affective experience. A recent quantitative meta-analysis of 12 attachment-based interventions by van IJzendoorn, Juffer, and Duyvesteyn (1995) demonstrates that behaviorally oriented, short-term interventions are consistently effective in increasing parental sensitivity, and, to a lesser extent, in ameliorating children's attachment insecurity.

During the preschool years, basic patterns of attachment are transformed reflecting developments in language and cognition, as well as shifting issues in psychosocial adjustment. For the child experiencing a secure relationship, there is a new partnership with the caregiver that reflects these advances and allows for increased autonomy within and beyond the dyad (Erikson, 1963; Sroufe, 1983). Within the dyad, the secure strategy incorporates perspective-taking, mutual communication of affect and desires, and joint planning; however, a number of deviations from this pattern are possible (Crittendon, 1992; Sroufe, 1989). Insecure attachment to the primary caregiver in infancy has been identified as one predictor of later preschool behavior problems, including anxiety, high dependency on adults, social withdrawal, passivity, submissiveness with peers, and internalizing symptoms in general (Erickson, Sroufe, \& Egeland, 1985; LaFreniere \& Sroufe, 1985; Lewis, Feiring, McGuffog, \& Jaskir, 1984; Rubin \& Mills, 1991; Sroufe, 1983).

From a behaviorist perspective as well, many studies can be cited that show a relationship between various aspects of childrearing and child outcomes. These studies provide convergent data implicating maternal sensitivity as a major factor in the socialization of competent behavior in early childhood. For example, Putallaz (1987) reports associations between peer sociometric status and maternal involvement and maternal affect, suggesting that mothers of socially competent children are more sensitive to their child's feelings and more likely to use reason rather than coercion when compared to mothers of less competent children, supporting similar conclusions drawn by Baumrind (1967) a generation earlier. 
Deviations from an optimal goal-corrected partnership involving mutuality and give and take between parent and child, as well as firm limit setting when necessary by the parent, may be viewed in terms of the balance of power in the parent-child relationship. Research has generally shown that mothers of aggressive children can be undercontrolling, permissive, or inconsistent in contexts that call for limit setting, only acting predictably by reliably failing to set firm limits when the child escalates, a pattern aptly described as "coercion training" (Dumas, LaFreniere, \& Serketich, 1995; Patterson, Reid, \& Dishion, 1992). In contrast, mothers of anxious-withdrawn preschoolers appear to be overcontrolling and intrusive, particularly in situations that call for mutuality and negotiation, rather than the exercise of parental authority. For example, in a joint problem solving situation, LaFreniere and Dumas (1992) report the virtual absence of contingent positive affect and behavior, replaced instead by an indiscriminant pattern of negativity coupled with high levels of intrusive and controlling behavior. Despite the precise description of the proximate processes regulating the dyadic interaction between parent and child, studies of this sort fall short of demonstrating causality.

Because of the correlational nature of many of the early studies relating child rearing styles to socialization outcomes, a number of questions have been raised regarding direction of effects (Bell, 1968), and more recently, whether these early studies, or their modern counterparts, show any nongenetically determined socialization effects at all (Rowe, 1994). Because of the confounding of genes and environment in all (or nearly all) studies on the effects of childrearing styles or attachment patterns on child development, Rowe asserts that instead of providing an alternative explanation for the impact of genes on personality traits and psychosocial disorders, such "socialization science" demonstrates the heritability of such traits, including childrearing styles. Since "genes can influence variations in child-rearing style ... the association of child-rearing styles and children's traits can be 'spurious' (noncausal)" (p. 21).

The present study incorporates a preven- tive intervention within an experimental design in order to address these issues of causality and direction of effects. Although few in number, intervention studies employing control groups can provide an effective means of demonstrating childrearing effects (see, for example, Patterson, Chamberlain, \& Reid, 1982). In the present study, we have (a) targeted a group of mothers, not on the basis of their symptomatology, (e.g., depressed mothers), but on the basis of emotional/behavioral problems displayed by their children outside the home; (b) conducted a multifaceted intervention specifically for these mothers, but without directly intervening with the children, and (c) evaluated outcome in the children's behavior in the preschool classroom as assessed by the teacher. Because preschool teachers were blind to experimental-control designation and because there was no direct intervention in the preschool classroom, we view this type of design as capable of generating the strongest type of scientific evidence for direct socialization effects and the possibilities of change stemming from a focus on the child's primary relationships.

\section{Method}

\section{Subjects}

Children who participated with their mothers were part of a large-scale evaluation of the socioemotional adjustment of children attending preschool on a regular basis. Relying on standardized teacher ratings (see below), a sample of 43 anxious-withdrawn children (23 girls, 20 boys) was selected from a large sample of French-Canadian preschoolers recruited from 74 different preschool classrooms in the Montreal Metropolitan area. Children ranged in age from 31 to 70 months, with a mean age of 53.4 months.

Children whose scores were $1.0 S D$ or more above the mean for their gender on the anxious-withdrawn scale of the SCBE were contacted. From a total of 137 children evaluated as "anxious-withdrawn," 43 (31.4\%) of the mothers consented to participate in the study. Next boys and girls were alternately assigned to the experimental or control group assuring random assignment or a roughly 
Table 1. Comparisons between treatment and control groups for sociodemographic characteristics

\begin{tabular}{lcccc}
\hline \hline \multicolumn{1}{c}{$\begin{array}{c}\text { Sociodemographic } \\
\text { Characteristics }\end{array}$} & $\begin{array}{c}\text { Treatment } \\
(n=21)\end{array}$ & $\begin{array}{c}\text { Control } \\
(n=22)\end{array}$ & $t$ & \\
\hline Mother's age & 34.05 & 32.00 & 1.04 & n.s. \\
Mother's education (years) & 13.71 & 13.41 & 0.31 & n.s. \\
Child's age & 54.29 & 52.55 & 0.70 & n.s. \\
Daycare experience (months) & 26.25 & 22.81 & 0.84 & n.s. \\
& & & $\chi^{2}$ & \\
\cline { 2 - 5 } & & & & \\
Child's sex & & & & \\
$\quad$ Girl (\%) & 57.1 & 50.0 & 0.22 & n.s. \\
$\quad$ Boy (\%) & 42.9 & 50.0 & & \\
Family earnings & & & & \\
$\quad<39,999(\%)$ & 71.4 & 72.7 & 0.00 & n.s. \\
$\quad>\$ 40,000(\%)$ & 28.6 & 27.3 & & \\
Marital status & & & & \\
$\quad$ Biparental $(\%)$ & 47.6 & 63.6 & 1.12 & n.s. \\
$\quad$ Monoparental $(\%)$ & 52.4 & 36.4 & & \\
\hline \hline
\end{tabular}

equivalent number of boys and girls to each group. Because of the relatively small size of the groups, assessments of the age and gender of child, age of mother, maternal education, marital status and family income, and child's SCBE evaluation were made to verify whether randomized assignment had its intended effects. As shown in Table 1, none of these variables differed significantly between the experimental and control groups. Of the 43 subjects who consented to participate, subject attrition was limited to a single subject who withdrew from the study just prior to its debut.

\section{Procedures and Measures}

The treatment group received an intensive 6month intervention, while the control group did not. Experimental subjects were assessed through maternal reports of parenting stress, direct observation of maternal warmth and discipline and child motivation/cooperation during a filmed problem solving interaction with their child, and teacher ratings of competence and anxious-withdrawn behavior using the SCBE prior to the intervention and again on all measures 6 months later at the end of the intervention. The control group was assessed on one occasion for all measures in the same manner as the experimental group, except for the SCBE which was assessed twice. Repeated assessments were carried out for the SCBE measures only, using the same 6-month interval as for the experimental group.

Social Competence and Behavior Evaluation (SCBE) (formerly Preschool Socio-affective Profile, PSP). This 80-item Likert rating scale was developed to provide information about emerging problem behaviors as well as competencies in children of preschool age (LaFreniere, Dumas, Capuano, \& Dubeau, 1992; LaFreniere \& Dumas, 1995). It was chosen for this study because of its focus on affective expression and emotional regulation in the context of social interaction in the classroom and its extensive validation on a French-Canadian population. The questionnaire, completed by the child's preschool teachers, yields three factors: social competence, angeraggression, anxiety-withdrawal. The interrater reliability of the three factors was uniformly high $(.86, .85, .83)$. This represents the average reliability across all pairs of teachers in the preschool classrooms evaluated, $N=994$. Factors were internally consistent as indexed by Cronbach's $\alpha(.92, .90, .85)$, and assessments of test-retest reliability with an interval of 2 weeks between tests revealed high corre- 
lations $(.86, .82, .78)$ across the three scales. Recently, these psychometric characteristics were replicated on two samples (over 1500 children) in the United States, attesting to the robustness of the instrument (LaFreniere \& Dumas, 1995).

Subjects were rated by their teachers at the end of the fall semester providing the children with a minimum of 3 months to adjust to the preschool setting, while providing the teachers with an adequate amount of time to observe the children under their care. As with our previous research, subjects were selected for the study using a cutoff of one standard deviation above the mean on the anxiety-withdrawal scale, which is composed of items describing anxious, depressed, isolated, and overly dependent behavior. It is similar to previous indices labeled as affective disorder or internalizing symptoms, though somatic complaints, eating and sleeping irregularities, and similar problems were not included in the item list because of the preschool context of the evaluation. In previous validation research (LaFreniere et al., 1992), an anxious-withdrawn group selected using this cutoff was observed to be significantly less interactive than all other groups, though not necessarily neglected or rejected by their peers. These anxious-withdrawn preschoolers spent much of their time in activities on the periphery of group life, such as onlooking and parallel play, and were also prone to be alone and unoccupied. Teachers characterize these children as sad, depressed, tired, and worried, as well as isolated. They show little interest in the activities that their peers typically delight in. These children tend to have poor self-concepts and to show high levels of immaturity, as they often seek adult attention in situations that do not require it, and find it difficult to perform tasks within their capabilities without regular assurance, giving up easily where other children would persist.

More importantly for the purposes of this study, the mothers of these anxious-withdrawn preschoolers were observed to be significantly different than mothers of average or competent preschoolers in a filmed problemsolving situation with their preschooler. These mothers were characterized by an absence of contingent positive affect and behavior, and an indiscriminant pattern of negativity coupled with high levels of intrusive and controlling behavior (LaFreniere \& Dumas, 1992).

Parenting Stress Index. This instrument (Abidin, 1990) provides an empirically derived measure of the degree of stress a parent experiences in the childrearing role. The index has satisfactory reliability and validity and discriminates adequately between clinic-and nonclinic-referred and abusive and nonabusive families. It has been translated into French with extensive validation and normalization on a French-Canadian sample, including the demonstration of associations between parenting stress and preschool behavior problems (Bigras, LaFreniere, \& Abidin, 1996). Besides predicting problem behaviors in French-Canadian preschoolers, parenting stress scores above the 90th percentile are highly associated with other behavioral and contextual risk factors (LaFreniere \& Dumas, 1995).

Laboratory task. This method was selected because of our previous research demonstrating associations between maternal affect and behavior and preschoolers' anxious-withdrawn behavior (LaFreniere \& Dumas, 1992). It is based on a paradigm developed by Gauvain and Rogoff (1989) and subsequently adapted by us for use with preschool children. Mothers were invited to come with their child to a university laboratory to participate in a "grocery task" game. The mother-child dyads were greeted by a research assistant upon arrival and taken to the laboratory where the experimental task was shown and explained to them. The task consisted of planning an efficient route through a miniature grocery store laid out as a 3-dimensional board game on a $71 \times 61 \mathrm{~cm}$ table which a 3-4-year-old could easily reach while standing. In previous research with preschoolers this task taxed the capacity of the child for coordinating affect, cognition, and behavior, and for drawing upon their mother's assistance and support when needed (Dumas \& LaFreniere, 1993; LaFreniere and Dumas, 1992).

Fifty-six miniature items of general use 
were arranged on six shelves on each side of three rows and on four shelves along the inside of the store's outer walls. The items were grouped in the following categories: vegetables (five items), fruit (six), meat and fish products (six), dairy products and frozen foods (nine), candy (four), baked goods (seven), toiletries (10), cereals and grains (six), and pasta and sauce (three). After explaining the task to the child and the mother through instruction and modeling, the child was given a practice "shopping list" consisting of three $8 \times 12 \mathrm{~cm}$ cards with easily identifiable pictures of items available in the store. The child was then asked to move a small toy "shopper" through the store to "buy" each item, while abiding by three simple rules: (a) make the "shopper" take the shortest path to the item, (b) do not allow the "shopper" to fly over the store to reach an item, and (c) do not allow the "shopper" to buy items not on the shopping list. Following this practice session, the experimenter clarified the instructions or provided additional information if needed. After making sure that both child and mother understood the game, the experimenter presented the child with different lists of five items each for up to five separate trials, but made no further intervention except to verify that the child recognized all five items on the list before each new "shopping trip." After each list was completed, the child checked out the groceries using a Fisher-Price toy register. Mothers were instructed to assist the child as needed in the completion of the game for the first three shopping lists, but not to complete the task for the child. After completion of three lists, or after $18 \mathrm{~min}$ if three lists had not been completed, the experimenter invited the mother to complete a different task on an adjacent table and the child to continue the grocery task alone, with the understanding that at any time the mother could assist the child or the child could ask her for help if needed. Children then completed two "shopping trips" alone or worked on the task for 6 min, whichever came first.

\section{Observational rating scales}

Three 7-point scales were developed, based in part on rating scales originally developed by
Matas, Arend, and Sroufe (1978) to score mother-child interaction in a problem solving situation expressly designed to surpass the child's ability in solving the problem independently. The first two scales assessed maternal behavior involving emotional support and appropriate control or direction to the child, while the third scale assessed the child's behavior in the task involving motivation. Each of these variables was assessed on a 7-point scale. A high score on any scale involved meeting two major criteria. For the mother to receive a high score on emotional support, the two major criteria were (a) expressing positive affect and approval in a responsive, contingent manner, and (b) providing appropriate, well-timed support and encouragement. Low scores were characterized by apathetic, indifferent, irritable, sarcastic, or denigrating behavior toward the child.

A high score on appropriate control involved (a) proactive control, including initiating coherent demands and requests, and structuring the task for the child, and (b) reactive control that is effective in redirecting the child's attention or deescalating minor conflicts or frustrations. A low score would be obtained for either ineffectual, undercontrol involving the absence of limit setting when needed, or harsh, punitive overcontrol, involving rigid, excessive demands and conflict escalation.

The child was scored on level of motivation using the major criteria of (a) enthusiasm for the task, including interacting with the mother as expressed in rapid engagement, and expressions of positive affect and pleasure, and (b) interest, including exploration of the materials, questions and comments, persistence of on-task behavior, and spontaneous reinvolvement following any obstacles or distractions.

A team of three experienced observers (two advanced graduate students and a faculty researcher) trained for 2 months to systematize the scoring of the videotapes. All observers were blind to the status of the subjects. The 63 sessions were each scored by two different observers working independently at different times, thus interrater agreement was calculated for all 63 tapes. Percent- 
age agreement ranged from 71 to $85 \%$ across the three scales with an average agreement of $75.2 \%$. Raters were accorded an agreement when they were within 1 scale point and differences of less than 3 points were averaged to produce the final rating. Differences of 3 points or more were rare $(8 \%)$ and were rescored with all three observers present, with the observer who did not initially score the tape responsible for the final rating.

\section{Treatment program}

The outline below provides a capsule summary of the general program composed of 20 sessions, divided into four phases, spread over a 6-month period. The five home visitors (advanced graduate students) were trained by experienced professionals using an 80-page manual, available in French (Capuano, 1995). The training involved reading, group discussions, and role playing. In addition, the second author provided extensive individual and group supervision at regular intervals in order to insure the fidelity of the intervention program across different home visitors and over the duration of the study. The following summary provides a very brief outline of the contents/goals of the intervention program:

Phase 1: Assessment of maternal and family characteristics, and mother-child interaction (one lab visit, two home visits). In the assessment phase, the mother and child initially visited the research laboratory in order to be videotaped in the structured task described above. This visit lasted approximately $45 \mathrm{~min}$, at the end of which mothers were given two questionnaires (PSI, and a brief social and demographics form) to be completed prior to the home visit.

The first home visit took place within 1 week of the lab visit and was informal in character. The home visitor's main objective was to establish a positive rapport with the mother and her child, provide a general outline of the program in terms of its contents and duration, and the commitment required of each participant. The PSI and demo were collected and the mothers were encouraged to describe their current family situation in greater detail.

Phase 2: Caregiver focused education on child's developmental needs (three home visits). This educational phase was structured by a five-volume set of readings dealing with basic issues of child development and parental concerns published in French and English by Sante et Bien-etre Social Canada (1991). These five booklets dealt with the following topics: Development, Behavior, Security, The Body, and Parental Needs. Each week the home visitor brought one or two volumes to provide a basis for a 1-hr discussion covering the topic of the volume(s); booklets were provided for all parents on a complimentary basis.

Phase 3. Determination of specific objectives (two home visits). At the seventh visit, the home visitor, after having consulted with the research team, presented a synthesis of all the observations as well as the mother's comments made during the previous lab and home visits. Working with the mother, the home visitor elaborated a list of specific objectives, including personal and parental concerns, and situations that the mother targeted as habitually difficult with her child. During this visit, the home visitor explained several distinct practices that would be carried out in the forthcoming visits for all participants, for example, child-directed play sessions (Speltz, 1990), parenting skills training (Blechman, 1985), the use of the videotape of the mother's interaction with her child during the lab visit, etc. Thus, while each mother could ask for assistance in any particular aspect of her relationship with her child, a core set of activities and objectives were provided by the home visitors to all mothers in the program.

During the eighth visit, all mothers viewed the filmed interaction with their child with the home visitor. Prior to this visit, the home visitor viewed the video with the research team in order to identify any conflicts or difficulties, as well as characteristic strengths, that were apparent both in the filmed interaction and throughout the home visits. This joint viewing allowed mothers to express their 
thoughts and feelings regarding their attitudes and behaviors toward their child, as well as explanations and attributions concerning their child's behavior and emotions.

Phase 4. Realization of the intervention plan (11 home visits). The preceding 10 visits provided a vital context for the more focused sessions that would dominate the course of the intervention for the next several months. Beginning with the ninth visit (and lasting to the 19th) each visit was divided into three half-hour periods dealing with the following three general concerns: principles of childdirected interaction during mother-child play, problem behavior modification and parenting skills training, and building a more effective network of social support.

In summary, a 6-month experimental intervention incorporating components from attachment, attributional, and behaviorist perspectives was implemented in order to (a) increase the mother's understanding of the developmental needs of the preschool aged child, (b) promote parenting competence in terms of sensitivity to these needs, (c) alleviate parenting stress, and (d) provide social support. We hypothesize that the level of maternal involvement in the therapeutic process will be positively related to adaptive maternal functioning at outcome, assessed by pre-post measures of parenting stress, as well as behavioral measures of mother-child interaction in the laboratory. Most importantly, we also predict a subsequent increase in social competence and reduction of child behavior problems in the preschool.

\section{Results}

In this home intervention study, mothers and their preschool children in both treatment and control groups were assessed on a battery of measures involving maternal self-report, behavioral observations of mother-child interaction, and teacher ratings of the children in the preschool classroom. The results are organized within three types of analyses: (a) within-group comparisons between the preand posttests for the treatment group; (b) between-group comparisons between the treatment and control group; and (c) an ANCOVA using SCBE change scores (posttest minus pretest) with age as a covariate.

Table 2 presents the means and standard deviations for all six outcome measures, and the $t$ tests for the within group pre-versus posttests. All six dependent measures showed significant differences indicating positive changes for the treatment group immediately following a 6-month intervention. Table 3 presents the means and standard deviations for the six outcome measures, and the $t$ tests for the between group comparison (treatment vs. control groups). In this more stringent analysis, focusing on whether the positive changes previously noted may be attributed to the intervention, four of the six dependent measures were significant (one marginal) and the magnitude of these differences was attenuated in three out of four cases.

The total parenting stress scores for mothers in the treatment group showed a significant decline over the 6-month interval between pre- and posttest $(t=2.31, d f=40, p<$ .01 , one-tailed); however, this decline cannot be unambiguously attributed to the treatment since the treatment-control comparison is not significant $(t=1.20, d f=40, p>.05)$. In more clinical terms, this group of mothers of anxious-withdrawn children scored at the 74th percentile at pretest and at the 58th percentile at posttest, though it is unclear from these results why this change occurred.

The behavioral ratings showed a pattern of results consistent with our hypotheses of behavioral change in the interaction of the mother with her child and the child's level of motivation and cooperation with the parent. Mothers in the treatment group showed an increase in emotional support toward their child ( $t=1.94, d f=40, p<.05$, one-tailed $)$ and more appropriate control $(t=3.27, d f=40$, $p<.01$, one-tailed), though only the latter was significant in the treatment-control comparison $(t=3.10, d f=40, p<.01$, one-tailed). In addition, children in the treatment group showed an increase in positive motivation significant in both the within-group $(t=2.91, d f$ $=40, p<.01$, one-tailed) and between-group comparison $(t=2.13, d f=40, p<.05$, onetailed).

Because SCBE teacher ratings were the ba- 
Table 2. Pre-and posttest scores on outcome assessments for treatment group

\begin{tabular}{|c|c|c|c|c|c|}
\hline & \multicolumn{5}{|c|}{ Scores } \\
\hline & \multicolumn{2}{|c|}{$\begin{array}{c}\text { Pretest } \\
(n=21)\end{array}$} & \multicolumn{2}{|c|}{$\begin{array}{l}\text { Posttest } \\
(n=21)\end{array}$} & \multirow[b]{2}{*}{$t$} \\
\hline & $\bar{X}$ & $S D$ & $\bar{X}$ & $S D$ & \\
\hline Parenting stress (PSI) & 259.0 & 48.7 & 240.0 & 45.7 & $2.31 * *$ \\
\hline Maternal affect & 3.55 & 1.4 & 4.17 & 1.6 & $1.94 *$ \\
\hline Maternal control & 3.36 & 1.5 & 4.57 & 1.4 & $3.27 * *$ \\
\hline Child motivation & 3.98 & 1.5 & 4.98 & 1.3 & $2.91 * *$ \\
\hline Social competence (SCBE) & 77.8 & 20.3 & 113.1 & 28.5 & $6.32 * * *$ \\
\hline Anxiety-withdrawal (SCBE) & 55.6 & 8.2 & 73.9 & 12.2 & $7.03 * * *$ \\
\hline
\end{tabular}

${ }^{*} p<.05$, one-tailed; ${ }^{* *} p<.01$, one-tailed; ${ }^{* * *} p<.001$, one-tailed.

Table 3. Treatment versus control group scores on outcome assessments

\begin{tabular}{|c|c|c|c|c|c|}
\hline & \multicolumn{5}{|c|}{ Scores } \\
\hline & \multicolumn{2}{|c|}{$\begin{array}{c}\text { Treatment } \\
(n=21)\end{array}$} & \multicolumn{2}{|c|}{$\begin{array}{l}\text { Control } \\
(n=21)\end{array}$} & \multirow[b]{2}{*}{$t$} \\
\hline & $\bar{X}$ & $S D$ & $\bar{X}$ & $S D$ & \\
\hline Parenting stress (PSI) & 240.0 & 45.7 & 255.5 & 38.4 & 1.20 \\
\hline Maternal affect & 4.17 & 1.6 & 3.62 & .9 & 1.35 \\
\hline Maternal control & 4.57 & 1.4 & 3.30 & 1.2 & $3.10 * *$ \\
\hline Child motivation & 4.98 & 1.3 & 4.12 & 1.3 & $2.13^{*}$ \\
\hline Social competence (SCBE) & 113.1 & 28.5 & 91.7 & 30.7 & $1.99^{*}$ \\
\hline Anxiety-withdrawal (SCBE) & 73.9 & 12.2 & 61.7 & 11.4 & 1.60 \\
\hline
\end{tabular}

${ }^{*} p<.05$, one-tailed; ${ }^{* *} p<.01$, one-tailed.

sis of the selection of extreme groups of subjects for both the experimental and control groups, prepost comparisons are less relevant because of the anticipated regression toward the mean. Treatment and controls were compared on their posttest scores only. These comparisons revealed a significant increase in teacher-rated social competence for children whose mothers were in the treatment group $(t=1.99, d f=40, p<.05$, one-tailed); however, the analysis for anxious-withdrawn behavior was only marginally significant $(t=$ $1.60, d f=.40, p=.07$, one-tailed). Relative to their same-sex peers, children in the treatment group rose from the lowest $10 \%$ to the 46th percentile on their mean ratings for social competence, and dropped from the 94th percentile to the 63rd percentile for anxiouswithdrawn behaviors.
In addition to the posttest only $t$ tests, analysis of covariance were conducted on SCBE change scores (the difference between each child's pre- and posttest measure) with child's chronological age in months as a covariate and the experimental/control designation as the between-subjects factor. Significantly greater, positive change was found for the experimental group over the control group for social competence $(F(1,37)=4.38, p<.05)$, but not for anxiety-withdrawal $(F(1,37)=$ 1.19 , n.s.). No significant covariate effect of age was found for either social competence $(F(1,37)=.56$, n.s. $)$ or anxiety-withdrawal $(F(1,37)=.24$, n.s. $)$.

\section{Discussion}

A rigorous multimethodological assessment showed generally consistent positive results 
for this 6-month intervention conducted in the home. The most important findings indicate that anxious-withdrawn preschool children whose mothers participated in the home intervention showed significant improvement in social competence as assessed through teacher ratings in the classroom. Because preschool teachers were blind to experimental-control designation and because there was no direct intervention in the preschool classroom, we view this finding as strong evidence for the potency of transactional processes underlying early affective disorders, and for direct socialization effects of parenting practices on the child.

Secondary to this finding are more equivocal data concerning the process of changing the course of mother-child interaction or maternal characteristics. For example, maternal reports of parenting stress indicate significant change over time, but not when treatmentcontrol posttests are compared, suggesting that this measure may reflect a subjective positive bias or expectation of participating mothers. Convergent evidence of a more qualitative nature also supports this view. Based upon extensive interviews with a psychologist who was not part of the intervention team, mothers reported high levels of global satisfaction $(90 \%)$ with the program. By themselves these qualitative and subjective indices provided by mothers in the intervention group, while encouraging for the staff, do not provide sound scientific evidence for the efficacy of this intervention, and in general such indices should always be supplemented with outcome measures that are not open to contamination.

In this sense, we believe that more substantial evidence for treatment effects comes from the more labor intensive observational ratings produced by observers who were blind to the identities of the parents who participated in the treatment and control groups. While it is unclear from these data to what extent characteristic patterns of maternal warmth may be directly modified from an intervention of this sort, it is certainly clear that the mother's degree of controlling and intrusive parenting behaviors can be influenced by a combination of providing information about the develop- mental issues in the period of early childhood, insight on attributional processes affecting a parent's emotional response to child unresponsiveness, and specific training in childcentered interactions for parents who are prone to be intrusive and overcontrolling in interaction with their preschooler. While the design of the present study does not allow for the assessment of the efficacy of any one component, in some cases it appeared that a mother who actually views a video of her interaction with her child is more able to recognize the bidirectional nature of the conflictual interaction during the structured laboratory task and less likely to attribute the source of the conflict to her child alone. It should be noted that this component of the intervention was initiated only in the context of a supportive relationship with her regular home visitor. By the midway point in the intervention (10th visit), mothers were more willing to explore their thoughts and feelings regarding their child and any problems they were currently experiencing in their parenting role. For some mothers who were unaccustomed to relinquishing control to the child in any context, the child-directed play sessions could be unsettling and afforded another occasion for discussing their fears and attributions surrounding this issue of control. Unfortunately, we did not employ an attributional outcome measure in this study. However, it became apparent during the intervention that maternal attributions and the emotions associated with them could pose potential barriers to the process of altering the mother's behavior in relation to her child.

This speculation is supported by Bugental and colleagues (Bugental, 1991; Bugental \& Shennum, 1984; Bugental, Blue, \& Cruzcosa, 1989) who have repeatedly demonstrated that child responsiveness has a selective effect on mothers as a function of their perceived control. Mothers with low perceived control in their caregiver role tend to react poorly to children who ignore or are slow to respond to questions and suggestions. In contrast, mothers with high attributed control produce more positive consequences with unresponsive children, by virtue of their failure to react negatively to this behavior pattern. Bugental inter- 
prets these results as manifestations of selffulfilling prophecies that serve to maintain the mother's belief system. Mothers with attributions of low control perceive unresponsive children as difficult and react in ways that maintain difficult child behavior. The subsequent unresponsiveness that they elicit from the children could reasonably confirm their belief that they have little power to ensure successful interaction with these children. As part of the transactional nature of their distressed relationship, the child's noncompliance is likely to lead the parent to use more intrusive and controlling behaviors that ultimately function to promote more negative emotionality and noncompliance from the child.

Similar cycles, shown to characterize the sequential interactions of mother-child relationships of anxious-withdrawn children (Dumas \& LaFreniere, 1993; LaFreniere \& Dumas, 1992), can be altered through developmentally based preventive interventions. Further evidence for this belief comes from changes produced in the child's behavior as a result of this intervention strategy even though it was explicitly not directed at the child. The behavioral ratings in a joint problem solving task revealed a positive change in the child's level of motivation toward sustaining positive and cooperative interchanges with the parent. We do not view this result as particularly surprising since previous research using conditional probability analyses of child responsiveness has shown that anxious-withdrawn children exhibit a high degree of reciprocity with their caregiver in positive behavior and affective expression (and aversive behavior and negative affective expression), contingently matching the immediately preceding behavior or affect of their mothers (LaFreniere \& Dumas, 1992). Based on this reciprocity principle, it follows that successfully altering changes in the caregiver's behavior will produce subsequent changes in the child's behavior.

One other study of which we are aware has also recently documented the efficacy of parent-child interaction training for preschoolers with behavioral problems. Strayhorn and Weidman (1991) conducted an indicated preventive intervention in which low-income parents were offered four to five 2-hr group sessions with instruction and roleplaying on various aspects of parenting, including behavioral management and individual play with their children. Results at 1-year follow-up showed significant improvements in treatment subjects when compared with controls on teacher-rated behavior problems, including assessments of ADHD. In their study, improved parenting practices following the intervention were predictive of more positive child outcomes 1 year later.

We view these results and our own as supporting the causal hypotheses advanced by previous investigators who demonstrated linkages between preschooler's social competence/behavior problems and various measures of childrearing style or quality of the parent-child relationship. These results support the inclusion of a parent-training component in a developmentally based program to promote social and emotional competence in preschoolers, although several caveats in the present study should be mentioned. Perhaps the most important concerns the manner in which parents are recruited for their participation in a treatment program. In the present study, this was a voluntary decision made by approximately one-third of the mothers contacted. No particular failure or stigma was attached to their participation, though some mothers freely admitted that they felt they could use some information and assistance regarding the socialization of their preschooler. We have no means of knowing how effective the same program would be if it were conducted without this free and voluntary choice by these mothers, but we suspect that this might be an important factor in predicting a successful home intervention. Certainly these results do not generalize to a home intervention program that is mandated without the free and voluntary consent of the parent.

We also note that our choice to intervene in the home was made solely for the purpose of building a substantial case for the direction of socialization effects. It does not follow from our study that we believe that other forms of intervention would be ineffective with anxious-withdrawn preschoolers. Recent research indicates that a school-based preven- 
tive intervention designed to promote emotional competence in somewhat older children can be effective, particularly in children with higher teacher ratings of psychopathology (Greenberg, Kusche, Cook, \& Quamma, 1995). Earlier research has also supported the use of same-age and younger-aged peers to reduce socially withdrawn behavior in preschool children (Furman, Rahe, \& Hartup, 1979), a practice we routinely use outside of the present experimental context.

Another aspect of the present study that merits discussion concerns the goal of this preventive intervention. Because of the relatively high cost of the treatment component of the study we chose to intervene only in cases of children showing moderate to extremely high levels of anxiety and social withdrawal in the preschool classroom. Because children were identified by their teachers as having detectable signs foreshadowing mental disorder, but falling short of any DSM-IV diagnostic levels, our treatment would be classified as an indicated preventive intervention as delineated by the Institute of Medicine's recent report (IOM, 1994). However, the key finding of our study indicates that children whose mothers participated showed significant improvement as assessed through teacher ratings of social competence in the classroom. This is not surprising since the intervention was consciously designed to promote the well being of the mother and enhance her parental confidence and competence. In our view, by virtue of its positive formulation (promotion of parental health and competence, rather than reduction of child symptoms) such a preventive intervention minimizes any potential risk of participation, and may possibly maximize potential benefits. From the standpoint of prevention, we view an increase in social competence as a significant achievement for these preschool children since early investigators have reported better prediction of later disorder from "various forms of competence and ego maturity rather than the absence of problems and symptoms as such" (Kohlberg, LaCrosse, \& Ricks, 1972, p. 1274). The social competence scale taps a broad range of behaviors designed to assess the positive qualities of the child's adaptation, rather than specific behavioral competencies. As a devel- opmental construct, social competence refers to behaviors that indicate a well-adjusted, flexible, emotionally mature, and generally prosocial pattern of social adaptation. In previous validation work with the SCBE-80 (LaFreniere et al., 1992), the socially competent group was highest in peer sociometric status. Because of its qualitative dimension, sociometric status is one of the most robust correlates of teacher ratings of social competence in preschoolers.

In the present study, reduction of anxiouswithdrawn behavior with peers in the experimental group was nearly as great in magnitude as the increase in social competence, but failed to reach significance when compared to a control group. Several factors must be considered when evaluating this failure to find significant between-group differences in anxious-withdrawn behavior. First, at a descriptive level, teachers who were blind to the identity of the children in the intervention group did rate these children collectively at the 63rd percentile, well below the cutoff point of clinical concern on this scale, and well below their average score prior to the intervention (94th percentile). While statistically significant, these changes cannot be attributed to the intervention alone. They certainly involve, in part, a regression to the mean, as the changes over time in the control group indicate. The implication of these results for future research are clear and we would recommend temporal stability in the child's anxious-withdrawn behavior as a criterion for subject selection in future intervention studies.

Second, it is possible that structural, homeostatic characteristics of the peer group limited the social reintegration of these children who were initially withdrawn during the very active process of the social organization of their groups. This speculation is supported by naturalistic observational research showing a high degree of stability in preschool social structures of attention and affiliation over the course of the academic year (LaFreniere \& Charlesworth, 1983; Vaughn \& Waters, 1981). For the purpose of demonstrating transactional effects we conducted this intervention in the home with the mother, rather than in the preschool with the teacher and the children. In 
a comprehensive program of prevention of anxious-withdrawn behavior, interventions in both settings - involving parents, teachers, and peers-could be effectively combined.

Several other caveats related to the present study should also be mentioned. For maternal ratings and measures derived from laboratory interaction, a posttest-only control group design was employed, allowing for relatively greater investment of limited resources in the intervention itself. According to Campbell and Stanley (1963),

While the pretest is a concept deeply embedded in the thinking of research workers in education and psychology, it is not actually essential to true experimental designs. For psychological reasons it is difficult to give up "knowing for sure" that the experimental and control groups were "equal" before the differential experimental treatment. Nonetheless, the most adequate all-purpose assurance of lack of initial biases between groups is randomization. Within the limits of confidence stated by the tests of significance, randomization can suffice without the pretest. (p. 25)

Consistent with the view of Campbell and Stanley is the fact that the pretest means of

\section{References}

Abidin, R. R. (1990). Parenting Stress Index: Test manual (3rd ed.). Charlottesville, VA: Pediatric Psychology Press.

Baumrind, D. (1967). Child care patterns anteceding three patterns of preschool behavior. Genetic Psychology Monography, 75, 43-88.

Bell, R. (1968). A reinterpretation of the direction of effects in studies of socialization. Psychological Review, 75, 81-95.

Bigras, M., LaFreniere, P. J., \& Abidin, R. (1996). Indice de Stress Parental: Edition Francaise. Toronto: Multi-Health System.

Blechman, E. A. (1985). Solving behavior problems at home and at school. Champaign, IL: Research Press.

Bugental, D. B. (1991). Affective and cognitive processes within threat-oriented family systems. In I. E. Sigel A. V. McGillicuddy-Delisis, \& J. J. Goodnow (Eds.), Parental belief systems: The psychological consequences for children (2nd ed., pp. 219-248). Hillsdale, NJ: Erlbaum.

Bugental, D. B., \& Shennum, W. A. (1984). Difficult children as elicitors and targets of adult communication patterns: An attributional-behavioral-transactional analysis. Monographs of the Society for Research in Child Development, 49(1, Serial No. 205).

Bugental, D. B., Blue, J., \& Cruzcosa, M. (1989). Perceived control over caregiving outcomes: Implications for child abuse. Developmental Psychology, 25, 532-539. the treatment group closely match those of the control group (which are also uninfluenced by any treatment) on all the dependent variables.

In conclusion, the demonstration of significant effects of an intervention in the home with the mother on the child in the preschool confirm the transactional model underlying this study and demonstrate the potential utility of a home-based component in intervention programs for the prevention of behavioralemotional problems in young children showing early symptoms in the preschool setting. While difficult to conduct, studies using preventive interventions to investigate the intricate interplay of affect, cognition, and behavior among parents and children involved in normal and dysfunctional relationships will help to clarify difficult, but clinically significant, issues of the direction of effects that correlational or longitudinal data leave unresolved. The strategic interplay of laboratory and field studies, and naturalistic and experimental methods, can also provide a more ecologically sensitive means of testing, extending, and elaborating current models of developmental psychopathology.

Campbell, D. T., \& Stanley, J. C. (1963). Experimental and quasi-experimental designs for research. Boston: Houghton Mifflin.

Capuano, F. (1995). Evaluation d'une intervention dans le milieu familial auprès de mères dont les enfants d'age préscolaire sont anxieux et isoles. Thèse de Doctorat non-publiée, Université de Montreal.

Cicchetti, D. (1993). What developmental psychopathology is about: Reactions, reflections, projections. $D e$ velopmental Review, 13, 471-502.

Cicchetti, D., \& Toth, S. L. (1992). The role of developmental theory in prevention and intervention. Development and Psychopathology, 4, 489-493.

Cicchetti, D., Toth, S. L., \& Lynch, M. (1995). Bowlby's dream comes full circle: The application of attachment theory to risk and psychopathology. In T. H. Ollendick \& R. J. Prinz (Eds.), Advances in clinical child psychology (Vol. 17). New York: Plenum Press.

Crittenden, P. M. (1992). Treatment of anxious attachment in infancy and early childhood. Development and Psychopathology, 4, 575-602.

Crockenberg, S. (1981). Infant irritability, mother responsiveness and support influences on the security of infant-mother attachment. Child Development, 52, $857-865$.

Dumas, J. E., \& LaFreniere, P. J. (1993). Mother-child relationships as sources of support or stress: A comparison of competent, average, aggressive, and anxious dyads. Child Development, 64, 1732-1754. 
Dumas, J. E., LaFreniere, P. J., \& Serketich, W. J. (1995) Balance of power: A transactional analysis of control in mother-child dyads involving socially competent aggressive, and anxious children. Journal of Abnormal Psychology, 104(1), 104-113.

Emde, R. N. (1989). The infant's relationship experience: Developmental and affective aspects. In R. N. Emde \& A. J. Sameroff (Eds.), Relationship disturbances in early childhood (pp. 33-51). Basic Books: New York.

Erickson, M. F., Korfmacher, J., \& Egeland, B. R. (1992). Attachments past and present: Implications for therapeutic intervention with mother-infant dyads Development and Psychopathology, 4, 495-507.

Erickson, M. F., Sroufe, L. A., \& Egeland, B. (1985). The relationship between quality of attachment and behavior problems in preschool in a high-risk sample. In I. Bretherton \& E. Waters (Eds.), Growing Points of Attachment Theory and Research (Monographs of the Society for Research in Child Development, Serial No. 209, Vol. 50. Nos. 1-2), 147-166.

Erikson, E. (1963). Childhood and society (2nd ed.). New York: Norton.

Furman, W., Rahe, D., \& Hartup, W. (1979). Rehabilitation of socially withdrawn preschool children through mixed age and same age socialization. Child Develop ment, 50, 915-922.

Gauvain, M., \& Rogoff, B. (1989). Collaborative problem solving and children's planning skills. Developmental Psychology, 25, 139-151.

Greenberg, M. T., Kusche, C. A., Cook, E. T., \& Quamma, J. P. (1995). Promoting emotional competence in school-aged children: The effects of the PATHS curriculum. Development and Psychopathology, 7, 117-136

IOM (Institute of Medicine) (1994). Reducing risk for mental disorders: Frontiers for preventive interven tion research. Washington, D.C.: National Academy of Sciences Press.

Jacobson, S. W., \& Frye, K. F. (1991). Effect of maternal social support on attachment: Experimental evidence. Child Development, 62, 572-582.

Kellam, S. G. (1990). Developmental epidemiologic framework for family research on depression and aggression. In G. R. Patterson (Ed.), Depression and aggression in family interaction (pp. 11-48). Hillsdale, NJ: Erlbaum.

Kohlberg, L., LaCrosse, J., \& Ricks, D., (1972). The predictability of adult mental health from childhood behavior. In B. B. Wolman (Ed.), Manual of child psychopathology. New York: McGraw-Hill.

Koretz, D. (1991). Prevention-centered science in mental health. American Journal of Community Psychology, 19, 453-458.

LaFreniere, P. J., \& Charlesworth, W. R. (1983). Dominance, affiliation and attention in a preschool group: A nine-month longitudinal study. Ethology and Sociobiology, 4, 1-14.

LaFreniere, P. J., \& Dumas, J. E. (1992). A transactiona analysis of early childhood anxiety and social withdrawal. Development and Psychopathology, 4(4), 385-402.

LaFreniere, P. J., \& Dumas, J. E. (1995). Social competence and behavior evaluation, preschool edition. Los Angeles: Western Psychological Services.

LaFreniere, P. J., \& Dumas, J. E. (1995). Behavioral and contextual manifestations of parenting stress in mother-child interaction. Early Education and Development, 6(1), 73-91.
LaFreniere, P. J., Dumas, J., Dubeau, D., \& Capuano, F. (1992). The development and validation of the preschool socio-affective profile. Psychological Assessment: Journal of Consulting and Clinical Psychology, 4(4), 442-450.

LaFreniere, P. J., \& Sroufe, L. A. (1985). Profiles of peer competence: Interrelations among measures, influence of social ecology, and relation to attachment history. Developmental Psychology, 21, 56-69.

Lewis, M., Feiring, C., McGuffog, C., \& Jaskir, J. (1984). Predicting psychopathology in six-year-olds from early social relations. Child Development, 55, 123136.

Lieberman, A. F., Weston, D. R., \& Pawl, J. H. (1991). Preventive intervention and outcome with anxiously attached dyads. Child Development, 62, 199-209.

Matas, L., Arend, R., \& Sroufe, L. A. (1978). Continuity of adaptation in the second year: The relationship between quality of attachment and later competence. Child Development, 49, 547-556.

Patterson, G. R., Reid, J. B., \& Dishion, T. J. (1992). Antisocial boys. Eugene, OR: Castalia.

Putallaz, M. (1987). Maternal behavior and children's sociometric status. Child Development, 58, 324-340.

Rowe, D. C. (1994). The limits of family influence: Genes, experience, and behavior. New York: Guilford Press.

Rubin, K. H., \& Mills, R. S. L. (1991). Conceptualizing developmental pathways to internalizing disorders in childhood. Canadian Journal of Behavioral Science, 23, 300-317.

Sante et Bien-etre Social (1991). Programme Y'a personne de parfait.

Speltz, M. L. (1990). The treatment of preschool conduct problems: An integration of behavioral and attachments concepts. In M. T. Greenberg, D. Cicchetti, \& E. M. Cummings (Eds.), Attachment in preschool years (pp. 399-426). Chicago: University of Chicago Press.

Sroufe, L. A. (1983). Infant-caregiver attachment and patterns of adaptation in preschool: Roots of maladaptation and competence. In M. Perlmutter (Ed.), Minnesota symposia on child psychology, 16. Hillsdale, NJ: Erlbaum.

Sroufe, L. A. (1989). Relationships, self and individual adaptation. In R. N. Emde \& A. J. Sameroff (Eds.), Relationship disturbances in early childhood (pp. 7094). New York: Basic Books.

Sroufe, L. A., \& Fleeson, J. (1986). Attachment and the construction of relationships. In W. Hartup \& Z. Rubin (Eds.), Relationships and development (pp. 5171). Hillsdale, NJ: Erlbaum.

Sroufe, L. A., \& Rutter, M. (1984). The domain of developmental psychopathology. Child Development, 55, 17-29.

Strayhorn, J. M., \& Weidman, C. S. (1991). Follow-up one year after parent-child interaction training: Effect on behavior of preschool children. Journal of the American Academy of Child and Adolescent Psychiatry, 30, 138-143.

Van IJzendoorn, M. H., Juffer, F., \& Duyvesteyn, M. G. C. (1995). Breaking the intergenerational cycle of insecure attachment: A review of the effects of attachment-based interventions on maternal sensitivity and infant security. Journal of Child Psychology and Psychiatry, 36, 225-248.

Vaughn, B. E., \& Waters, E. (1981). Attention structure, sociometric status and dominance: Interrelations, behavior correlates and relationships to social competence. Developmental Psychology, 17, 275-288. 